\section{$\underset{\substack{\text { hommes } \\ \text { \& migrations }}}{ }$}

\section{Hommes \& migrations}

Revue française de référence sur les dynamiques

migratoires

\section{$1293 \mid 2011$}

L'immigration dans les musées

\title{
Les hommes libres
}

Film français d'Ismaël Ferroukhi

\section{André Videau}

\section{Q OpenEdition \\ 1 Journals}

\section{Édition électronique}

URL : http://journals.openedition.org/hommesmigrations/540

DOI : 10.4000/hommesmigrations.540

ISSN : 2262-3353

\section{Éditeur}

Musée national de l'histoire de l'immigration

\section{Édition imprimée}

Date de publication : 1 septembre 2011

Pagination : 155

ISSN : 1142-852X

\section{Référence électronique}

André Videau, «Les hommes libres », Hommes \& migrations [En ligne], 1293 | 2011, mis en ligne le 29 mai 2013, consulté le 22 septembre 2020. URL : http://journals.openedition.org/hommesmigrations/ 540 ; DOI : https://doi.org/10.4000/hommesmigrations.540

Ce document a été généré automatiquement le 22 septembre 2020.

Tous droits réservés 


\title{
Les hommes libres
}

\author{
Film français d'Ismaël Ferroukhi
}

\section{André Videau}

11942 : Paris occupé est géré par les autorités collaborationnistes de Vichy. Elles mettent tout leur zèle à appliquer les directives de l'ennemi. Les juifs font partie des populations plus particulièrement visées par la répression. Ils sont stigmatisés (port de l'étoile jaune, exclusion de la fonction publique...) et bientôt traqués, arrêtés, déportés.

2 Sait-on que parmi les réseaux d'entraide qui prirent de gros risques pour leur porter secours, figurent un certain nombre de musulmans résidant en France, première vague de l'immigration maghrébine, alors désignés comme mahométans et bénéficiant d'un statut de neutralité ?

3 Par exemple, à l'ombre rassurante du minaret de la Mosquée de Paris, entre bassins d'ablutions

4 et salles de prière, on a distribué des faux papiers et des subsides, on a caché des enfants et favorisé des évasions. Tout cela s'est opéré sous la houlette du recteur Si Kaddour Ben Ghabrit, homme discret et fin diplomate, dévoué au sultan du Maroc dont il partageait les vertus de tolérance.

5 C'est dans de tels interstices des histoires officielles qu'un certain nombre de jeunes réalisateurs d'origine maghrébine estiment de leur devoir d'opérer un travail de réparation mémorielle. Citons, entre autres, Rachid Bouchareb, Roschdy Zem, Bourlem Guerdjou, Ismaël Ferroukhi... Au-delà de la prise en compte d'épisodes méconnus et du refus de leur utilisation partisane, il y a la confrontation éclairante avec les réalités d'aujourd'hui.

6 Petite frappe sans le moindre idéal politique, Younes (après son rôle écrasant dans Un prophète de Jacques Audiard, Tahar Rahim tient la route) est venu en France pour faire du marché noir. On dirait aujourd'hui du "trabendo". La police ne tarde pas à le serrer et à lui mettre un marché en main. Ses petits trafics n'intéressent pas la Gestapo. Elle préférerait savoir ce qui se trame derrière les murs de la Mosquée où son allure de musulman novice et dûment circoncis inspirera confiance. C'est donnant-donnant. Younes pourrait être à la croisée des chemins : déchéance d'un salaud, avènement d'un 
héros. Ni l'un, ni l'autre. En quelques rencontres fortuites ou provoquées, il va découvrir qu'une guerre peut en cacher une autre et que "les hommes libres" ont parfois plusieurs combats à mener, simplement il y a un ordre de priorité. La lutte contre le nazisme n'est pas incompatible avec la lutte contre la colonisation. Le vénérable Recteur de la Mosquée protège les enfants juifs et aussi les militants clandestins du mouvement nationaliste algérien dirigé par Messali Hadj très présent dans l'immigration. On peut comme Leïla (Lubna Azabal, émouvante combattante de l'ombre) sacrifier l'amour pour des idées. Ou comme Salim Halili (Mahmoud Shalaby) tout sacrifier pour la musique.

7 Accaparé par ses calculs égoïstes, Younes, qui n'avait rien vu venir, reçoit toutes ces leçons de plein fouet. C'est celle de l'amitié, doublement improbable, pour un juif, pour un homosexuel qui le bouleverse le plus. Pas de véritable héros positif. Pas de parcours globalement édifiant. Une histoire d'hommes rudement transcrite et sobrement réalisée, à laquelle Benjamin Stora a donné sa caution historique. 